\title{
Communication
}

\section{Planetary Health Ethics: Beyond First Principles}

\author{
Alexander Foster ${ }^{1, *(\mathbb{D})}$, Jennifer Cole ${ }^{2, * \mathbb{D}}$, Andrew Farlow ${ }^{3}$ and Ivica Petrikova 4 \\ 1 School of Anthropology and Museum Ethnography, Oxford University, Oxford OX2 6PE, UK \\ 2 Department of Geography, Royal Holloway University of London, Egham TW20 0EX, UK \\ 3 Oxford Martin School, Oxford University, Oxford OX1 3BD, UK; andrew.farlow@oriel.ox.ac.uk \\ 4 Department of Politics and International Relations, Royal Holloway University of London, \\ Egham TW20 0EX, UK; ivica.petrikova@rhul.ac.uk \\ * Correspondence: alexander.foster@anthro.ox.ac.uk (A.F.); Jennifer.cole@rhul.ac.uk (J.C.); \\ Tel.: +44-7815-530-951 (A.F.); +44-7847-756-474 (J.C.)
}

Received: 6 December 2018; Accepted: 12 February 2019; Published: 15 February 2019

\begin{abstract}
Planetary health is a transdisciplinary approach that aims to advance the understanding of the links between human-driven changes to the planet and their consequences, and to develop appropriate solutions to the challenges identified. This emerging movement has not yet agreed upon a code of ethics to underpin the rapidly expanding body of research being carried out in its name. However, a code of ethics might support the principles for planetary health set out in the Canmore Declaration of 2018. Phrases such as "Public Health 2.0", "Human Health in an Era of Global Environmental Change", or "A safe and just operating space for humanity" are often used in planetary health discussions, but are not always clearly defined and so far, the field lacks a strong guiding ethical framework. In this paper, we propose a starting point towards a code of ethics for planetary health that builds on the Canmore Declaration. We chose to propose 12 ethical principles in recognition of the need for a 12-Step Programme for the planet. The human race must identify and reject damaging behaviours. Evidence of the harm we are causing the planet is no longer enough and refraining from certain current practices is essential for Earth's future health. We must motivate advocacy and calls for action. We believe a shared ethical code can act as a tool to enable and encourage that process. This paper is presented to the planetary health community as a starting point, not as a finished agenda. We welcome comments, critiques, additions and the opportunity to rework our approach accordingly.
\end{abstract}

Keywords: planetary health; ethics; principles

\section{Introduction}

Planetary health is a transdisciplinary approach that aims to advance the understanding of the links between human-driven changes to the planet and their consequences [1], and to develop appropriate solutions to the challenges identified [2]. However, it does not yet have an ethical code that can act as an agreed base against which identified solutions can be evaluated. The aim of this paper is to propose a starting point for planetary health ethics, building on the Statement of Principles set out in the Canmore Declaration of 2018 [3], which itself builds upon the 1986 Ottawa Charter for Health Promotion [4]. Both affirm the urgent need to consider the health of people, places and the planet as indistinguishable.

We propose 12 ethical principles that might act as a roadmap towards the admirable goals inherent in the existing principles, though what we set out here is a work in progress and it is not intended to represent a finished product. We seek input and collaboration from the wider academic and non-academic community to critique, refine and amend our approach in order to ensure the ethical underpinning we suggest is collaboratively agreed upon and mutually acceptable to all stakeholders. 
At the heart of our reasoning for why such an ethical underpinning is required is the subtle difference between "principles" and "ethics". Principles are aspirational [5], but also generally abstract. Ethics are more practical and tangible. They are standards that can be adhered to (or violated), and they guide the choices that we make in our daily lives, such as, should I drive a car that emits greenhouse gases when I could walk? Or, should I spend money on entertaining myself when I could give that money to the poor [6]? Such decisions inevitably require us to choose one course of action and its consequences, over another course of action with different consequences. Ethics do not provide incontrovertible answers. They can be highly controversial and politically loaded, and finding consensus on what they should be will not be easy, particularly in a pluralistic world [7]. However, they do provide a base for ethical reasoning, from which principles can be put into practice. They can, therefore, provide a basis for negotiating actions in situations where decisions on whether or not to act, and how to act, is neither unanimous nor the preferred first choice of all actors [7]. In this sense, the notion of ethics carries with it something bigger than the sense of the individual, pushing us towards actions that are not (only) for self-interest [6].

Ethical judgements thus empower us to transcend our own likes and dislikes and to reason with others as to why they should do the same. Inherent in traditional ethics are concepts such as honesty, prudence, avoiding harm and concern for others [7]. If we can extend the notion of "others" to other species inhabiting the Earth and to the Earth itself, we can more easily ensure the "sustainable vitality of all systems" called for by the Canmore Declaration [3]. Ethics thus provide the foundation on which a principled framework for building a holistically healthier world can rest. For example, Colin Butler [8] has proposed updating existing ideas of epidemiology to the Anthropocene's "population of unprecedented size and connectedness", using the Canmore Declaration principles to encourage the embrace of spiritual thinking, concepts such as deep time [9] and indigenous philosophies. Human ingenuity should be able to better steward our natural resources; we suggest that the addition of an ethical code can help operationalize the principles on which we need to act in pursuit of that stewardship.

In drafting this ethical code, our foundation was the concept of Planetary Health as it was discussed in 2013, at the centennial gathering of the Rockefeller Foundation [10]. The gathering discussed the consequences of climate change and the impact of human activity on the environment, in particular, the future consequences of such actions. The notion that human health is intrinsically connected with the health of the planet is not new [11], and has been a firm part of traditional, indigenous knowledge in many parts of the world for decades. However, in contemporary discourse the concept re-emerged during the environmental movements of the 1970s [3]. In 1980 the environmental group, Friends of the Earth, attempted to expand the World Health Organization's definition of health to, "health is a state of complete physical, mental, social and ecological well-being and not merely the absence of disease[ ... ] personal health involves planetary health". Since that time, Planetary Health has become a unifying term in a growing movement that has focused on environmental sustainability and the impact of environmental degradation on human health. Its literature has demonstrated a strong focus on both practical application and ideological and academic study [12]. Active planetary health research programmes and networks are now supported by the Rockefeller Foundation Economic Council on Planetary Health based at the University of Oxford, UK [13], the Wellcome Trust [14], the Worldwide Universities Network (WUN) [15], and the Planetary Health Alliance, an international network of more than 70 research organizations [16]. A monthly peer-reviewed journal, Lancet Planetary Health [17] is entering its third year of publication. A growing number of universities are badging undergraduate and postgraduate courses to the field and running dedicated planetary health programmes.

\section{Capturing the Zeitgeist: Opportunities and Threats}

We must be mindful, however, of guarding against the movement slipping into a new form of eco-environmentalism and ensure that the language used remains attractive to policymakers, the business sector and economists, as well as ensuring it does not become a label by which products 
or practices can claim to be more environmentally friendly than they are. Planetary health discussions have become peppered with a series of phrases that seek to capture the zeitgeist of the approach but do not always contain much substance. "Public Health 2.0" [10] seeks to identify the key actions for the 21st century that will have a comparable impact to that of sanitation since the 19th century (and we should not forget that we have yet to achieve universally improved sanitation for all) [18]. "Human Health in an Era of Global Environmental Change" [19] considers the different trajectories of environmental change, such as urbanization, agricultural intensification, climate change and the increasing pollution of air, land and oceans as the vectors of human ill-health. Finally, "A safe and just operating space for humanity" [20] emphasizes the need to ensure that the development of developing countries is not held back by the developed world's need to conserve limited (ecological) resources for its own use. Exactly how concepts such as social equity and justice, responsible and sustainable development, and achievement of high standards of living for all can be made to fit together is not yet well defined. Furthermore, the notion that the UN's Sustainable Development Goals can be achieved without unacceptable damage being inflicted on the Earth's ecosystems is being increasingly challenged [21], as is the possibility that the global average lifespan may have reached a peak from which it is now declining [22]. Planetary health needs to confront and embrace these difficult challenges if it is to successfully plot a course through them. It is here that ethics has particular purchase by providing a navigational tool through a series of options that may inevitably require compromises from some or all of its stakeholders.

\section{The Unique Approach of Planetary Health}

We believe that planetary health is unique and distinct from other academic fields concerned with health and wellbeing. It shares Global Health's focus on achieving health equity for all populations worldwide and One Health's aim to integrate the health of humans, animals and the environment [23]. It also shares EcoHealth's concerns with ecosystem sustainability as a foundation for human wellbeing [24]. Planetary health, however, places a stronger focus on the increasingly short time-frame in which humanity will be able to address the environmental changes that impact human health. Trade-offs may be required to protect and conserve the environment for future generations. For example, currently high levels of energy use, meat consumption and consumer economies may not be sustainable without significant social and economic transformations. In fact, they may not be sustainable at all. Most recently, the IPCC has spelled out the urgency with which we must act to keep climate change within manageable bounds $[25,26]$. Thus, ways to manage those trade-offs and compromises must be developed in an equally urgent timeframe.

\section{Thoughts into Action}

In 2014, the early manifesto for planetary health [1] expressed the need for such a field and described attributes it should have, such as a social movement, an attitude towards life and a philosophy for living that fosters resilience and adaptation. It did not, however, go as far as to set out how that movement might then achieve its aims or what its "philosophy for living" should be. There is a danger that if we do not promote principles that define the ethics of how we look after the planet, the scientific evidence we gather on the harm being committed will have little impact. Solutions that focus only on cost-effectiveness, economic opportunities and valuation of natural capital are too narrow and too vulnerable to political interests. Ethical principles provide more agency to individuals and communities in advocating for solutions that cannot be easily costed in financial terms, particularly those that improve subjective wellbeing rather than profits.

Evidence of the harm that we are causing the planet is no longer enough; refraining from certain current practices is essential for Earth's future health. We must motivate advocacy and action, and believe that a strong set of shared ethics can act as a tool to enable and encourage that process. By developing such a code of ethics, we can build on both the vision set out in the early manifesto [1] on the 12 principles for planetary health education [27] that guide how academics might approach it 
as a field, and on the Canmore Declaration Statement of Principles for Planetary Health [3]. We can take these works further, however, by initiating a road map for action and for how we might evaluate the end state we seek to achieve when action is taken. Discussion and consultation on what the ethical underpinnings of the movement must be open to as wide a community as possible.

\section{The Value of Interdisciplinarity}

Planetary health draws on a wide spectrum of academic disciplines-from evolutionary biology to ecology, from public health to earth sciences, from anthropology to economics. At its heart lie the interconnected concepts of the Earth System highlighted by the Planetary Boundaries [28] and the Sustainable Development Goals [29]. We propose that a unique aspect of planetary health is the manner in which it seeks to address the planetary boundaries and the Sustainable Development Goals (SDG) simultaneously, accepting that this may involve difficult trade-offs. Achieving SDG targets for all people, and equity for all regions of the world within current and future resource constraints is becoming increasingly difficult [21]. This forces us to confront humanity's relationship with the natural world, and thus seek ways that might improve this eco-social relationship for the benefit of human health and wellbeing. The recent development of the Ecological Determinants of Health [30] sit alongside the World Health's Organization's Social Determinants of Health [31] as an underpinning that acess to health as a human right are steps in the right direction. Embedding their aims in an ethical code will help to socialize their intentions across the disparate communities that come together under the planetary health banner.

Elements of the ethical underpinning we propose may require scaling back from current ambitions. It may require a greater exploration of how compromises might be reached [7], and may benefit from a greater understanding of the social choice theory than has previously been applied [32,33]. It may also require greater input from those in business, corporate law and finance, sectors that may not always sit comfortably alongside environmentalism and ecoprotectionism, but they are a useful source in understanding how to leverage action. The seed planted by Christopher Stone in his 1973 paper "Should Trees Have Standing: Law, Morality and the Environment" [34] has grown into a mighty oak whose branches now spread their protection across the world. It gave agency to the environmental organization, Sierra Club, which opposed plans for a Californian ski resort in the mid-1970s, and its legacy can also be seen in the passing of the Te Urewera Act 2014, which afforded the New Zealand national park all the rights, powers, duties and liabilities of a legal person. The powers of the law to protect the rights of the planet are increasingly being recognized and leveraged [35]. Yet equally, law can be used as a lever to accept environmental harm but without it, progress towards a better standard of living might be impossible, in the short-term at least [36].

When compromises have to be made, ethics provide protection for the vulnerable as well as guidance to the powerful. As more compromises become necessary, there is likely to be an increasing need for us to learn how to manage compromise and disagreement [7]. Global pandemics, famines, refugee movements, failed states and climate change can only be addressed by the world as a whole [37], based on mutual trust as much as multilateralism, in which all partners feel valued and empowered to actively seek common ground, through formal deliberation if necessary. Compromise requires trust, respect, reciprocity and the absence of coercion [7]. All are admirable principles by which the entire world can be guided towards a new shared intentionality or sense of "we" - the characteristic that evolutionary anthropologist Michael Tomasello considers makes us uniquely human [38]. But we also need to learn how to do this in a world where optimal choices may no longer be available [32], and it is essential that we have a strong notion of what is, and what is not, viable.

\section{A 12-Step Programme for Earth}

We choose to organize our thinking into 12 ethical statements in recognition of the need for a 12-Step Programme $[39,40]$ for Earth. This recognizes that the human race must identify and reject damaging behaviours such as excessive energy use, food systems that drive land degradation and 
disposable consumerism. Refraining from practices such as these is not only essential for Earth's future health but may also provide navigation away from the Anthropocene towards a more holistic and protectionist coexistence with nature [41]. Planetary Health—checked by the ethics laid out here-can help lead us towards a better understanding of what we need to do and identify where we should refrain.

We group the 12 statements into three clusters to address the imagination challenges, information challenges [42], and implementation challenges identified by the Lancet-Rockefeller Commission on Planetary Health [2].

\section{Planetary Health Ethics: Beyond First Principles}

\subsection{Imagination Challenges}

1. Planetary Health involves the continual act of attunement to our bodies, the environment, the cultures we exist within, other inhabitants of the Earth and Earth's complete biosphere. Human actions should aim to inflict no harm on the planet.

2. Humans are inescapably part of the animal kingdom and of Earth's biosphere. Re-alignment with human evolutionary history, and an understanding of what costs or benefits may be involved when alignment is abandoned, should be an imperative for Planetary Health.

3. Planetary Health considers each human generation to be the custodians, not the masters, of Earth and its biosphere, responsible to future generations as well as to their own. We must leave the planet in a healthy state for future generations; they have equal rights to live on a healthy planet.

4. Planetary Health is a transdisciplinary ethos open to all. It does not belong to any one particular profession or social group. It not only requires voices to be heard from within academia, civil society, government (at all levels, especially at the local), the world of business and from outside traditional institutional powers, but also must facilitate the incorporation of these actors into a collaborative discussion.

\subsection{Knowledge Challenges}

5. The biosphere-particularly with regard to the potential for broad ecological diversity that exists within it-must be valued for its own sake, not only for the production of the food, medicines, and ecosystem services that are of benefit to humanity. New ways to understand, measure and value nature may require the entire biosphere to be afforded legal rights. It is insufficient and unjust to confer rights to individual nonhuman entities on the basis of how humans perceive it and/or on calculable economic measures, such as ecosystem services.

6. Improving human relationships with the natural world, and ultimately improving human health by reducing environmental damage, may challenge the current dominant paradigms of economic growth and development. We must not shy away from new ways of thinking about economic growth $[20,43]$ that eschew exponential growth rates forever if planetary damage is a byproduct. We must seek to redefine the notion of economic output and what it means to be productive. Planetary Health will benefit from indigenous populations' understandings of the value of air, land and sea.

7. Planetary Health workers must seek ways to balance equity of, and accessibility to, the past, present, and future benefits derived from human innovations. Future progress and development must not be impeded, but new benefits must not further stress the Earth System addressed by the planetary boundaries model. This will need us to critically debate and formulate new ways to deal with the complex equity issues at the heart of planetary health, that are simultaneously inter-generational, inter-species and social.

8. Early indications of ecosystem and planet-wide harm must be recognized and acted on at an international level with a fair sharing of the costs, assessed on ability to pay and responsibility 
for the damage caused. Practical alternatives to the cause of the harm must be developed, shared and implemented, not just discussed.

\subsection{Implementation Challenges}

9. As an ethos, Planetary Health must not only be a way of working, but also a way of living with which all people can engage. Active engagement with community groups and smaller organizations must be facilitated.

10. Planetary Health followers should attempt to enhance the early recognition of severe deviation from healthy environmental conditions and seek to realign human societies with their ecosystems at the earliest possible opportunity, supported by robust evidence of the detriments of inaction. Much of this evidence will be locally specific, requiring us to think globally and act locally.

11. Actions to address Planetary Health should follow a precautionary principle until we can identify where the risk of further deviation from optimal environmental conditions lies in future. We must also provide solutions and support for mitigating these risks, including strengthening the legal instruments for protection of nature [35]. This support may come in the form of financial and technological assistance, new legislation and structures of international governance, or knowledge sharing as appropriate. For each context, participatory approaches with local partners should be key to developing the best solutions.

12. A Planetary Health approach will provide the evidence on the basis of which sound policy decisions can be based and locally sensitive action taken. In the face of ideology and vested interests that often seek to ignore, denigrate, and undermine evidence, the Planetary Health approach must seek to sustain advocacy and action.

\section{Next Steps}

To reiterate, we do not see this list as exhaustive or final. It is presented as a starting point, not as a finished agenda. We welcome comments, critiques, additions and the opportunity to rework the ethical code accordingly. Planetary Health needs to be a collective endeavour in which everyone has a voice. In taking this forward we intend to create an inclusive endpoint drawn up through the conceptual framework of Collective Intelligence (CI) [44], enabling a collective platform of knowledge where anyone with access can contribute, thus creating a sum of knowledge greater than the sum of its parts. In doing so, we aim to draw on CI's organizational theory [45] as well as its technological applications [46]. We believe this has particular agency in the field of public health [47] as well as environmental solutions, and is perfectly placed to serve the aims of the planetary health movement. We welcome comments, criticisms and suggestions for further development.

Throughout 2019 we intend to collect comments on this ethical code through email surveys, active engagement with the international planetary health community through relevant conferences and workshops, through the online platform of the Planetary Health Alliance and through other suitable channels-including during fieldwork with communities in countries at all levels of development. We will directly contact academics working in the field through existing academic networks and by utilizing the contact details of corresponding authors published in relevant journals. Anyone wishing to contribute to the process should contact the corresponding authors with their comments. Our intention is to present a revised version of the ethical code, taking into account comments received, towards the end of 2019.

Author Contributions: This article has been a collaborative effort between the four authors. A.F. (Alexander Foster) was responsible for the initial conceptualization and writing-original draft preparation. A.F. (Alexander Foster). J.C. and A.F. (Andrew Farlow) were jointly responsible for shaping the ethics, investigation of the current literature and the methodology. J.C provided supervision and project administration. I.P. provided formal analysis, comments and criticism on the first draft. All four authors added to and shaped subsequent drafts of the paper and responded to the peer reviewers, thus providing validation, formal analysis, writing-review and editing. No software, data analysis or data curation was undertaken, nor was any funding acquired. 
Funding: No funding was obtained for this work.

Conflicts of Interest: The authors declare have no conflict of interest to declare.

\section{References}

1. Horton, R.; Beaglehole, R.; Bonita, R.; Raeburn, J.; McKee, M.; Wall, S. From public to planetary health: A manifesto. Lancet 2014, 383, 847. [CrossRef]

2. Whitmee, S.; Haines, A.; Beyrer, C.; Boltz, F.; Capon, A.G.; de Souza Dias, B.F.; Ezeh, A.; Frumkin, H.; Gong, P.; Head, P.; et al. Safeguarding human health in the Anthropocene epoch: Report of The Rockefeller Foundation-Lancet Commission on planetary health. Lancet 2015, 386, 1973-2028. [CrossRef]

3. Prescott, S.; Logan, A.; Albrecht, G.; Campbell, D.; Crane, J.; Cunsolo, A.; Holloway, J.; Kozyrskyj, A.; Lowry, C.; Penders, J.; et al. The Canmore Declaration: Statement of principles for planetary health. Challenges 2018, 9, 31. [CrossRef]

4. Potvin, L.; Jones, C.M. Twenty-five years after the Ottawa Charter: The critical role of health promotion for public health. Can. J. Public Health Revue Can. de Sante'e Publique 2011, 102, 244-248.

5. Knapp, S.; VandeCreek, L. A Guide to the 2002 Revision of the American Psychological Association's Ethics Code; Professional Resource Press/Professional Resource Exchange: Sarasota, FL, USA, 2003.

6. Singer, P. Practical Ethics; Cambridge University Press: Cambridge, UK, 2011.

7. Gray, B. (Bio) Ethics in a Pluralistic Society. Challenges 2019, 10, 12. [CrossRef]

8. Butler, C.D. Planetary epidemiology: Towards first principles. Curr. Environ. Health Rep. 2018, 5, 418-429. [CrossRef] [PubMed]

9. Berry, T. The Sacred Universe: Earth, Spirituality, and Religion in the Twenty-First Century; Columbia University Press: Portland, OR, USA, 2009.

10. Rockefeller, D. The role of foundations: Rockefeller Foundation. Public Health Rev. 2016, 37, 32. [CrossRef]

11. Prescott, S.L.; Logan, A.C.; Katz, D.L. Preventive Medicine for Person, Place, and Planet: Revisiting the Concept of High-Level Wellness in the Planetary Health Paradigm. Int. J. Environ. Res. Public Health 2019, 16, 238. [CrossRef]

12. Cole, J.; Bickersteth, S. What's planetary about health? An analysis of topics covered in The Lancet Planetary Health's first year. Lancet Planet. Health 2018, 2, e283-e284. [CrossRef]

13. Oxford University. Available online: https://www.planetaryhealth.ox.ac.uk/ (accessed on 2 May 2018).

14. Wellcome Trust. Available online: https://wellcome.ac.uk/what-we-do/our-work/our-planet-our-health (accessed on 2 May 2018).

15. Worldwide Universities Network. Available online: https://www.invivoplanet.com/ (accessed on 14 January 2019).

16. Planetary Health Alliance. Available online: https:// planetaryhealthalliance.org/ (accessed on 17 January 2019).

17. The Lancet Planetary Health. Available online: https://www.thelancet.com/journals/lanplh/issue/current (accessed on 17 January 2019).

18. Ferriman, A. BMJ readers choose the "sanitary revolution" as greatest medical advance since 1840. BMJ Br. Med J. 2007, 334, 111. [CrossRef]

19. Cole, J. Human Health in an Era of Global Environmental Change. In Report for the Rockefeller Foundation Economic Council on Planetary Health; Oxford Martin School: Oxford, UK, 2018.

20. Raworth, K. A safe and just space for humanity: Can we live within the doughnut. Oxfam Policy Pract. Clim. Chang. Resil. 2012, 13, 1-26.

21. O'Neill, D.W.; Fanning, A.L.; Lamb, W.F.; Steinberger, J.K. A good life for all within planetary boundaries. Nat. Sustain. 2018, 1, 88. [CrossRef]

22. Dong, X.; Milholland, B.; Vijg, J. Evidence for a limit to human lifespan. Nature 2016, 538, 257. [CrossRef] [PubMed]

23. Cole, J. Introduction to Planetary Health: Human Health in an Era of Global Environmental Change. CABI 2019, in press.

24. Wilcox, B.; Kueffer, C. Transdisciplinarity in EcoHealth: Status and future prospects. EcolHealth 2008, 5, 1-3. [CrossRef] [PubMed]

25. Intergovernmental Panel on Climate Change. Global Warming of $1.5^{\circ}$ C; IPCC: Geneva, Switzerland, 2018. 
26. Xu, Y.; Ramanathan, V.; Victor, D.G. Global warming will happen faster than we think. Nature 2018, 564, 30-32. [CrossRef] [PubMed]

27. Stone, S.B.; Myers, S.S.; Golden, C.D.; Group, P.H. Cross-cutting principles for planetary health education. Lancet Planet. Health 2018, 2, e192-e193. [CrossRef]

28. Rockström, J.; Steffen, W.; Noone, K.; Persson, Å.; Chapin, F.S., III; Lambin, E.; Lenton, T.M.; Scheffer, M.; Folke, C.; Schellnhuber, H.J.; et al. Planetary boundaries: Exploring the safe operating space for humanity. Ecol. Soc. 2009, 14, 2. [CrossRef]

29. Sachs, J.D. From millennium development goals to sustainable development goals. Lancet 2012, 379, 2206-2211. [CrossRef]

30. Hancock, T.; Spady, D.W.; Soskolne, C.L. Global Change and Public Health: Addressing the Ecological Determinants of Health; Canadian Public Health Association: Ottawa, Canada, 2016.

31. Solar, O.; Irwin, A. A Conceptual Framework for Action on the Social Determinants Of health; World Health Organisation: Geneva, Switzerland, 2010.

32. Sen, A. Maximization and the Act of Choice. Econom. J. Econom. Soc. 1997, 65, 745-779. [CrossRef]

33. Elster, J.; Hylland, A. (Eds.) Foundations of Social Choice Theory; CUP Archive; CUP: Kwun Tong, Hongkong, 1989.

34. Stone, C. Should trees have standing? In Nature's Web: Rethinking Our Place on Earth; M.E. Sharpe: Armonk, NY, USA, 1993.

35. Boyd, D.R. Recognizing the Rights of Nature: Lofty Rhetoric or Legal Revolution? Nat. Resour. Environ. 2018, 32, 13-17.

36. Atapattu, S. The Right to a Healthy Life or the Right to Die Polluted? The Emergence of a Human Right to a Healthy Environment Under International Law. Tulane Environ. Law J. 2002, 16, 65-126.

37. Morris, I. Why the West Rules-for Now: The Patterns of History and What They Reveal about the Future; Profile Books: London, UK, 2010.

38. Tomasello, M. Why We Cooperate; MIT Press: Cambridge, MA, USA, 2009.

39. Tonigan, J.S.; Toscova, R.T.; Connors, G.J. Spirituality and the 12-Step Programs: A Guide for Clinicians; American Psychological Association: Washington, DC, USA, 1999.

40. Nowinski, J. Facilitating 12-step recovery from substance abuse. Treat. Subst. Abus. Theory Tech. 2012, 3, 191-223.

41. Quilley, S. 20 Navigating the Anthropocene: Environmental politics and complexity in an era of limits. In Handbook on Growth and Sustainability; Edward Elger: Cheltenham, UK, 2017; Volume 439.

42. Gabrysch, S. Imagination challenges in planetary health: Re-conceptualising the human-environment relationship. Lancet Planet. Health 2018, 2, e372-e373. [CrossRef]

43. Dietz, R.; O'Neill, D. Enough Is Enough: Building a Sustainable Economy in a World of Finite Resources; Routledge: London, UK, 2013.

44. Malone, T.W. What Is Collective Intelligence and What Will We Do about It? In Edited Transcript of Remarks Made at the Official Launch of the MIT Center for Collective Intelligence; Earth Intelligence Network: Oakton, VA, USA, 2006.

45. Lévy, P. Collective Intelligence; Plenum/Harper Collins: New York, NY, USA, 1997.

46. Duhaime, E.P.; Olson, G.M.; Malone, T.W. Broad Participation in Collective Problem Solving Can Influence Participants and Lead to Better Solutions: Evidence from the MIT Climate CoLab; Collective Intelligence; Massachusetts Institute of Technology: Cambridge, MA, USA, 2015.

47. Cole, J.; Kleine, D.; Watkins, C. Internet discussion forums: Maximizing choice in health-seeking behaviour during public health emergencies. In Proceedings of the IEEE 2016 International Conference on Cyber Situational Awareness, Data Analytics and Assessment (CyberSA), London, UK, 13-14 June 2016.

(C) 2019 by the authors. Licensee MDPI, Basel, Switzerland. This article is an open access article distributed under the terms and conditions of the Creative Commons Attribution (CC BY) license (http://creativecommons.org/licenses/by/4.0/). 